\title{
Exploration on the Construction of Medical Basic Course System of Nursing Specialty in Higher Vocational Colleges
}

\author{
Hongtao Xu \\ Yancheng Vocational Institute of Health Sciences, Yancheng, 224006, China
}

Keywords: Higher vocational, Nursing, Medical basic course, System

\begin{abstract}
This paper through describing the problems in the basic medical education of nursing specialty in higher vocational colleges, analyzed the necessity of constructing the basic course system. The measures of constructing the basic course system of nursing specialty in higher vocational colleges are discussed.
\end{abstract}

\section{Introduction}

With the advance of the times and the development of the society, higher vocational education in our country is gradually becoming mature. How to cultivate the high level and high quality technical talents becomes the research subject of higher vocational education. Through the research, it is found that the reform of the basic curriculum and the construction of a reasonable medical curriculum system is an important measure to achieve the goal of the training of personnel.

\section{The problems of basic medical education in nursing specialty in Higher Vocational Colleges at present}

As a practical discipline, nursing students are required in the full understanding of the human body in the implementation of nursing. Basic medical course is a compulsory basic course of higher vocational nursing specialty, is the core curriculum of nursing education, and nursing personnel first course of study, which mainly includes the course of physiology, Pharmacology, pathology, Human Anatomy, Immunology, the histology and embryology, pathogenic biology and the biological chemistry, etc. [1], they connect with each other very close, only the grasp fully the knowledge, in order to promote the deepening of learning of nursing in the future. After the investigation and research, it is found that there are still a lot of problems in the medical basic course of nursing specialty in higher vocational colleges.

\section{Teaching method, teaching means are old}

In recent years, the development of nursing discipline is very fast, and a large number of emerging disciplines, resulting in the curriculum content of each course is increasing, the teaching task becomes more arduous. Teachers need to complete the teaching work of the complex teaching content in very limited teaching plan, so it can only use the traditional Infusion type teaching method. This makes the teachers in the teaching process to occupy the core and dominant position, weakening the students in the teaching process of the main role, a great blow to the enthusiasm and initiative of students learning, also stifle the development of creative thinking, make they in a very passive position. Not only that, the teachers are simple to teach students professional knowledge, only limited to the contents of the fixed teaching material, the teaching outline of the interpretation and explanation, tend to the biological, medical care teaching, but lack of effective education on the society and mental nursing. In this case, the training of nursing staff, only could do the present work in place, but due to the lack of good personality consciousness, and cannot improve their own level, it is difficult to meet the needs of high level and high quality of the community. 


\section{There is no innovation in teaching materials}

Although the education sector in recent years has carried out the reform of nursing professional materials, and has compiled some basic medical materials for higher vocational nursing professional, but it is regrettable that these materials are still in the use of the general basic medical teaching mode of the medical specialty, but simply increase or decrease the contents of the teaching materials, so it is difficult to help students to connect their medical knowledge with the nursing content, so that the teaching effect of nursing professional medical basic courses greatly reduce.

\section{Curriculum system is not perfect}

As far as the present situation is, the nursing professional education in higher vocational colleges is the result of the compression of the undergraduate education content [2], and the curriculum system of the undergraduate education is only a simplification and imitation of the clinical medical professional course, which lead many teaching content is more than the actual needs of the nursing discipline. At the same time, every course pays great attention to the integrity and system of the course, the relationship between subjects, the cross sex is not taken seriously very well, so the relevance of the professional reduced, practical also greatly weakened.

\section{Lack of effective practical teaching}

According to the results of the survey, the vast majority of higher education institutions are from secondary health school upgraded, so the laboratory function, structure and content is a single, can only open validity and simple experiment content. For a long time, lack of horizontal connection between subjects, leading to a comprehensive, design of the experiment is relatively lack, can not help students to master basic techniques and methods, cannot improve the students' overall skills, and thus lead to a "light practice and weight theory" phenomenon. Higher vocational colleges do not have scientific and reasonable arrangement of experiment course, the teaching hours of the experimental class is obviously less, and the experiment teaching is not carried out in time and effective reform. It is not able to cultivate the habit of students' practice. Not only that, in the experimental class is too much attention to the class rate of retention, neglect the improvement of the quality of the experiment. The existence of these problems, resulting in Higher Vocational College Students' practice ability is poor, and the ability to adapt to the work situation is poor, which restricts the development of nursing professional education.

\section{The necessity of constructing the basic course system of nursing specialty in Higher Vocational Colleges}

Target on the construction, production, management and service, to cultivate high quality skilled professionals meet the needs of the first line of high level, this is the most fundamental goal of higher vocational education [3]. Connect the higher vocational education of personnel training objectives with the vocational college nursing professional contact, shows that to provide technical skills, comprehensive quality of nursing personnel is higher vocational college nursing professional training objectives. In order to achieve the goal of nursing professional personnel training, teachers should change the traditional teaching mode, innovative teaching methods and teaching content, to further improve the students' professional ability.

In our country's Higher Vocational Colleges nursing education, it has been used in clinical medicine professional education mode, even so far, the nursing discipline has developed into an independent discipline, its set of medical basic course is still the clinical medicine professional imitation, not reflect the characteristics of nursing specialty. As time goes on, the drawbacks of the unscientific and irrational medical foundation course are gradually exposed. Therefore, it is necessary to reform the basic course of nursing specialty in Higher Vocational Colleges and to construct the basic course system of nursing specialty in higher vocational colleges, Cultivate high quality, high skill and high quality nursing talents. 


\section{Measures to construct the basic course system of nursing specialty in Higher Vocational Colleges}

\section{Start from the fact, and construct a reasonable system of medical basic courses}

In order to reflect the characteristics of higher vocational nursing education, deepen the reform in higher vocational nursing education teaching mode, cultivation of high-level, high-quality practical nursing talents, higher vocational colleges should proceed from fact construct scientific reasonable nursing profession basic medical curriculum system, integration of basic medical courses, strengthen the overall and practical. Therefore, higher vocational colleges should set up a medical basic course information exchange platform, can use the form of questionnaire to investigate the clinical nursing staff, and then through the exchange platform to organize teachers to analyze and summarize the feedback information of these vocational college nursing graduates. Through the analysis of feedback information to master the application of the knowledge of the graduates, to understand what knowledge can be applied directly in the actual operation, which also needs to be supplemented and adjusted. In questionnaire design, higher vocational colleges should strengthen the communication with the employer, in combination with the proposed organization of medical professional teachers to study, do a good job in the design of knowledge points, and ultimately form a strong clinical nursing workers targeted survey questionnaire. In the questionnaire, it can be used to distinguish the degree of knowledge points of medical basic courses through the necessary, need, and no need to set up.

After analyzing the feedback information of the questionnaire, according to the general cognitive law, the reasonable setting of the clinical nursing course is set up. Higher vocational colleges need of basic medical courses to be integrated, the physiological and pathological science, biochemistry, immunology, Physiology Learning Integration for human body function basis and application of nursing; pathology, histology and embryology, anatomy of the human body are integrated into human morphological basis and application of nursing; pathogen biology, pharmacology and parasite learn whole synthesis nursing and pharmacology.

\section{Strengthen practical teaching, cultivate students' practical ability}

Practical teaching is the core and key link in the teaching of medical basic course [4]. It not only can strengthen students' understanding of theoretical knowledge, but also can improve students' practical ability and cultivate their creative thinking. Under the new situation of nursing professional development, the traditional practice teaching mode, teaching method and teaching ideas have been unable to meet the needs of development, therefore higher vocational colleges must strengthen the reform of the experimental teaching of medical basic courses.

Firstly, higher vocational colleges need to reform the traditional experimental teaching method and teaching content, which will be closely combined with the experimental teaching organic, for example, the integration of pathogenic physiology, pharmacology and experimental teaching, and then set up a comprehensive functional experimental system. The experiment of cardiovascular system drugs, the drug delivery system, diuretics, and some central nervous system drugs were taught by the multimedia super experiment system.

Secondly, we should take the small class teaching mode, so that every student can enjoy the opportunity to practice, play their own initiative. Each class is about 15-18 people, 2-3 are a group, and then clear the division of each member of the group. Take this model increased the students practice opportunities, but also cultivate students' teamwork skills and have great effect on promoting the students' hands, brains ability and improving the basic medical courses teaching quality.

Thirdly, the experimental teaching of basic medical courses needs to increase innovative experiments, reduce the validation experiments. Because validation experiments are just a simple repetition of a given operation, there is no space to play, the initiative and enthusiasm of students learning will be a big blow. Therefore, it is necessary to increase the innovation experiment. Add the innovation experimental contents, the animal experiment can let the teachers guide students to design 
by themselves, make it clear that the different pharmacological action of adrenaline, noradrenalin, adrenaline. This can give full play to the creativity of students, and promote the development of their innovative ability.

Finally, higher vocational colleges can introduce the CAI courseware in the experimental teaching, and through the means of multimedia image of the display theory, experimental knowledge, open up the students' vision, enrich the students' imagination, change the original rigid, boring teaching, mobilize the initiative of students learning. At the same time, higher vocational colleges need to improve the campus network platform, so that students can continue to learn in their leisure time.

\section{Employ PBL teaching method, and strengthen the students' subjective consciousness}

PBL (problem based learning ) teaching method is the problem of learning, which is a problem based learning approach, emphasizing students autonomous learning under the guidance of problem [5]. USA neurology professor Barrow created PBL teaching method in 1969, and gradually widely used internationally. Its focus on the subject of cross combination, the teaching structure is mainly the modular teaching, dedicated to the training of high-level medical students. PBL teaching method, such as in the "lung" of the relevant content of the study, the team members to discuss and put forward problems, such as the location of the lung, morphological structure, etc., and then take the problem to collect information, analysis information, each group leader in the class discuss and communicate the results, the final evaluation of teachers. This mode strengthens the students' subject consciousness, and stimulates the students' learning enthusiasm, and then obtains the good teaching effect.

\section{Promote the implementation of bilingual teaching, and strengthen the times of nursing education in Higher Vocational Colleges}

Bilingual teaching is the teaching of Chinese and English. Because of the universality and the wide application of English in modern society, it is imperative to carry out bilingual teaching. Not only that, bilingual teaching can help students master the international advanced subject knowledge and subject concept, which is very important to realize the comprehensive development of students. Moreover, bilingual teaching is also an important way to meet the needs of the international compound talents in the domestic and international markets. Therefore, the nursing profession in higher vocational colleges should actively promote the implementation of bilingual teaching. Therefore, we should pay attention to two aspects work: firstly, we should strengthen the teachers' bilingual learning, improve their bilingual ability. Bilingual teaching for teachers to put forward higher requirements, so teachers should take the initiative to learn English, listening, speaking, reading and writing in four aspects to improve their English level, to ensure that students can be taught to students with professional knowledge of medical basic courses. Higher vocational colleges should organize the teachers to attend English training courses regularly, listen to the medical nursing professional courses, and promote the improvement of teachers' English. Secondly, generally speaking, higher vocational college nursing profession is three year system, if the content of bilingual teaching for students is less, can not achieve the expected teaching objectives, but if too many students do not meet the actual situation. Therefore, according to the students' English level, to develop appropriate targeted bilingual teaching objectives.

\section{Conclusion}

Generally speaking, the nursing profession in higher vocational colleges is only reform the basic curriculum, construct scientific and reasonable system of medical basic course, can develop the high level and high quality technical talents with the need of modernization development. Therefore, higher vocational colleges need to actively take the initiative to carry out medical basic curriculum reform, training high-quality nursing personnel, meet the needs of the modernization development. 


\section{References}

[1] JiangShan. The research on the basis of the modular design of the basic course of nursing specialty in higher vocational nursing students . Technology information, 2010,2 (17): 690

[2] WangGuiqiu, Wang J, Discussion on the overall optimization of the teaching content of the basic course of nursing specialty in Higher Vocational Colleges. Journal of Youjiang Medical College For Nationalities, 2014,36(1):131-132.

[3] XieYiqun, WangQianying. Basic courses in higher vocational nursing education open teaching exploration of. Commercial information, 2012, (30): 159

[4] Li Yu. Research and practice on nursing vocational education basic curriculum module. New curriculum learning - mid, 2014, (1): 40-40,41.

[5] XieYiqun. Analysis of higher vocational nursing specialty basic courses. Commercial Information, 2012, (18): 151-151. 